\title{
Complete genome sequence of Weeksella virosa type strain $\left(9751^{\mathrm{T}}\right)$
}

Elke Lang ${ }^{1}$, Hazuki Teshima ${ }^{2,3}$, Susan Lucas ${ }^{2}$, Alla Lapidus ${ }^{2}$, Nancy Hammon ${ }^{2}$, Shweta Deshpande ${ }^{2}$, Matt Nolan², Jan-Fang Cheng ${ }^{2}$, Sam Pitluck², Konstantinos Liolios ${ }^{2}$, loanna Pagani $^{2}$, Natalia Mikhailova ${ }^{2}$, Natalia Ivanova ${ }^{2}$, Konstantinos Mavromatis ${ }^{2}$, Amrita Pati ${ }^{2}$, Roxane Tapia ${ }^{2,3}$, Cliff $\mathrm{Han}^{2,3}$, Lynne Goodwin ${ }^{2,3}$, Amy Chen ${ }^{4}$, Krishna Palaniappan ${ }^{4}$, Miriam Land $^{2,5}$, Loren Hauser ${ }^{2,5}$, Yun-Juan Chang ${ }^{2,5}$, Cynthia D. Jeffries ${ }^{2,5}$, Evelyne-Marie Brambilla ${ }^{1}$, Markus Kopitz ${ }^{1}$, Manfred Rohde ${ }^{6}$, Markus Göker ${ }^{1}$, Brian J. TindalI ${ }^{1}$, John C. Detter ${ }^{2,3}$, Tanja Woyke $^{2}$, James Bristow ${ }^{2}$, Jonathan A. Eisen ${ }^{2,7}$, Victor Markowitz ${ }^{4}$, Philip Hugenholtz ${ }^{2,8}$, Hans-Peter Klenk ${ }^{1}$, and Nikos C. Kyrpides ${ }^{2 *}$

${ }^{1}$ DSMZ - German Collection of Microorganisms and Cell Cultures GmbH, Braunschweig, Germany

${ }^{2}$ DOE Joint Genome Institute, Walnut Creek, California, USA

${ }^{3}$ Los Alamos National Laboratory, Bioscience Division, Los Alamos, New Mexico USA

${ }^{4}$ Biological Data Management and Technology Center, Lawrence Berkeley National Laboratory, Berkeley, California, USA

${ }^{5}$ Lawrence Livermore National Laboratory, Livermore, California, USA

${ }^{6} \mathrm{HZI}$ - Helmholtz Centre for Infection Research, Braunschweig, Germany

${ }^{7}$ University of California Davis Genome Center, Davis, California, USA

${ }^{8}$ Australian Centre for Ecogenomics, School of Chemistry and Molecular Biosciences, The University of Queensland, Brisbane, Australia

*Corresponding author: Nikos C. Kyrpides

Keywords: strictly aerobic, slimy, Gram-negative, lyses proteins, inhabitant of mucosa, Flavobacteriaceae, GEBA

Weeksella virosa Holmes et al. 1987 is the sole member and type species of the genus Weeksella which belongs to the family Flavobacteriaceae of the phylum Bacteroidetes. Twentynine isolates, collected from clinical specimens provided the basis for the taxon description. While the species seems to be a saprophyte of the mucous membranes of healthy man and warm-blooded animals a causal relationship with disease has been reported in a few instances. Except for the ability to produce indole and to hydrolyze Tween and proteins such as casein and gelatin, this aerobic, non-motile, non-pigmented bacterial species is metabolically inert in most traditional biochemical tests. The 2,272,954 bp long genome with its 2,105 protein-coding and 76 RNA genes consists of one circular chromosome and is a part of the $\mathbf{G e}$ nomic Encyclopedia of Bacteria and Archaea project.

\section{Introduction}

Strain $9751^{\mathrm{T}}$ (= DSM $16922=$ NCTC $11634=$ JCM 21250 ) is the type strain of Weeksella virosa, which is the sole member and type species of the genus Weeksella [1,2]. The generic name was given in honor of O.B. Weeks for his contributions to the taxonomy of the genus Flavobacterium. The species epithet is derived from the Latin word 'virosa' meaning 'slimy', referring to the colony appearance of the species [1]. W. virosa strain $9751^{\mathrm{T}}$ was isolated from a clinical specimen of urine and described by Holmes and coworkers in
1986 [1]. These authors collected 29 strains from clinical samples, mostly obtained in the USA but also in other nations and continents, as the basis for their species description. Most isolates came from genitourinary tract samples, predominantly from women. Since then, strains of $W$. virosa were detected by cultural methods in the oral cavity [3], the genitourinary tract [4,5] of man, in clinical specimens of pigs [6], the urine of a cow with bladder carcinoma [7], and in the midgut of a Brazilian dipteran [8]. Weeksella-like strains were 
also found in food samples [9] and environmental samples, however, the latter matched the genus description but could not be assigned to the species virosa thus suggesting that they are representatives of additional species within the genus that are not yet described $[10,11]$. About $2 \%$ of healthy women carry $W$. virosa on their vaginal mucosa [4]. Two cases of peritonitis have been described as being caused by $W$. virosa $[12,13]$. Here we present a summary classification and a set of features for $W$. virosa $9751^{\mathrm{T}}$, together with the description of the complete genomic sequencing and annotation.

\section{Classification and features}

A representative genomic $16 \mathrm{~S}$ rRNA sequence of strain $9751^{\mathrm{T}}$ was compared using NCBI BLAST under default settings (e.g., considering only the highscoring segment pairs (HSPs) from the best 250 hits) with the most recent release of the Greengenes database [14] and the relative frequencies, weighted by BLAST scores, of taxa and keywords (reduced to their stem [15]) were determined. The five most frequent genera were Chryseobacterium (45.9\%), Wautersiella (23.2\%), Myroides (7.9\%), Elizabethkingia (7.3\%) and Empedobacter (7.0\%) (134 hits in total). Regarding the single hit to sequences from members of the species, the average identity within HSPs was $99.2 \%$, whereas the average coverage by HSPs was $96.8 \%$. Among all other species, the one yielding the highest score was Empedobacter brevis, which corresponded to an identity of $92.0 \%$ and an HSP coverage of $97.0 \%$. Accordingly, E. brevis groups as the sister genus in trees constructed from 16S rRNA gene sequences [16-19] whereas Bergeyella zoohelcum (family Flavobacteriaceae) is looked at as the phenotypic sister taxon which may be confused with $W$. virosa when applying traditional morphological and physiological tests [11]. The highest-scoring environmental sequence was GQ383925 ('sewage water isolate XJ109 Flavobacteriaceae str. XJ109'), which showed an identity of $92.5 \%$ and a HSP coverage of $98.5 \%$. The five most frequent keywords within the labels of environmental samples which yielded hits were 'skin' (11.2\%), 'human' (3.7\%), 'fossa' (3.4\%), 'microbiom, tempor, topograph' (2.8\%) and 'forearm' (2.1\%) (116 hits in total). The two most frequent keywords within the labels of environmental samples which yielded hits of a higher score than the highest scoring species were 'sewag, water' $(10.1 \%)$ and 'aerosol, air, citi, level, microarra, texa, two, urban' (10.0\%) (2 hits in total). From these sequence-based observations and the published culture-dependent detections (see above) it can be concluded that $W$. virosa occurs mainly as an inhabitant of mucosa of animals and man.

Figure 1 shows the phylogenetic neighborhood of strain $9751^{\mathrm{T}}$ in a $16 \mathrm{~S}$ rRNA based tree. The sequences of the five 16S rRNA gene copies in the genome differ from each other by up to three nucleotides, and differ by up to two nucleotides from the previously published 16S rRNA sequence (M93152), which contains eleven ambiguous base calls, and differ by up to 314 nucleotides from another previously published $16 \mathrm{~S}$ rRNA sequence (AF133539) which obviously represents a strain of the genus Bacteroides.

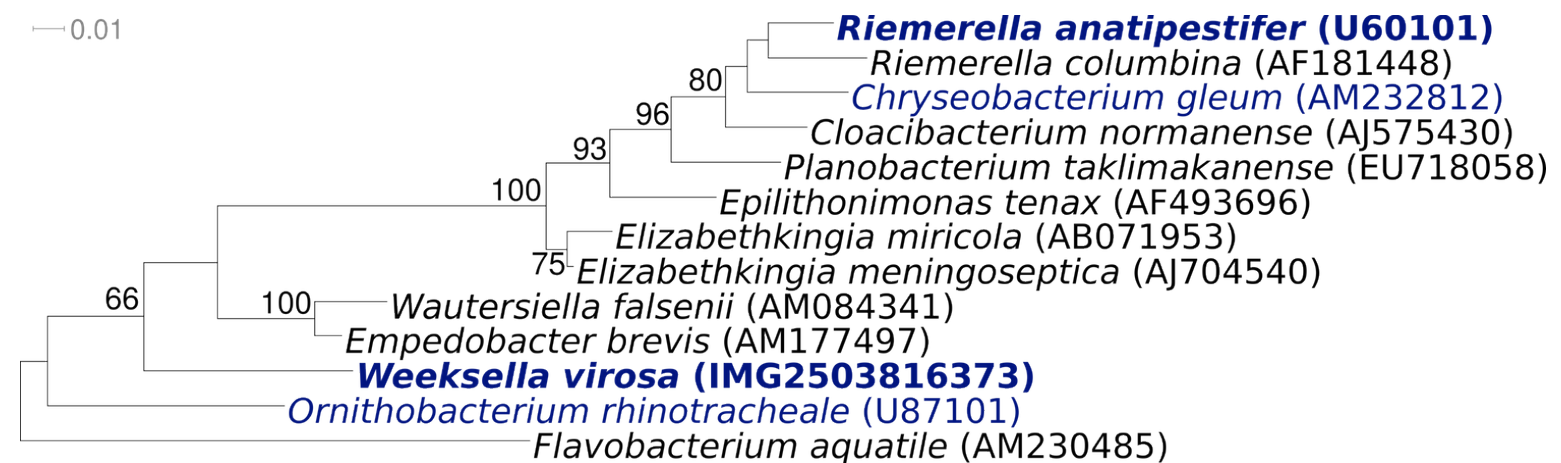

Figure 1. Phylogenetic tree highlighting the position of $W$. virosa relative to a selection of closely related other type strains within the family Flavobacteriaceae. The tree was inferred from 1,339 aligned characters [20,21] of the 16S rRNA gene sequence under the maximum likelihood criterion [22] and rooted in accordance with the type strain of the family. The branches are scaled in terms of the expected number of substitutions per site. Numbers above branches are support values from 700 bootstrap replicates [13] if larger than $60 \%$. Lineages with type strain genome sequencing projects registered in GOLD [23] are shown in blue, published genomes in bold. The genome of Riemerella anatipestifer will be described in this issue of SIGS [24]. 
The cells of $W$. virosa are rod-shaped $(0.6 \times 2.0-3.0$ $\mu \mathrm{m})$ with parallel sides and rounded ends (Figure 2). According to Holmes [1], the cells stain Gramnegative, are nonmotile and non spore-forming (Table 1). No intracellular inclusions such as polyhydroxybutyrate were detected. Colonies on nutrient agar appear circular and low convex with entire edges, smooth, shining and mucoid, reaching $2 \mathrm{~mm}$ in diameter after $24 \mathrm{~h}$ [1]. While the colonies are described as being non-pigmented on nutrient agar by most authors $[1,37]$, the production of a nondiffusible yellow pigment was reported during growth on blood agar [5]. Most strains produce a diffusible dark brown pigment on tyrosine-containing agar [1]. The strains grow at $42^{\circ} \mathrm{C}$ but not at $5^{\circ} \mathrm{C}$ [1]. W. virosa is a strictly aerobic chemoorganotroph and is not able to reduce nitrate, nitrite or selenite and does not acidify glucose or other sugars under standard conditions $[1,5]$. However, under test conditions developed for fastidious organisms such as Neisseria (API NH strips, Biomérieux), acid is produced from glucose [IDA] as is observed for the phylogenetic neighbors E. brevis and Wautersiella falsenii $[16,17]$. Cytochrome oxidase, catalase and phosphatase are present [1]. Tolerance to $\mathrm{NaCl}$ and $\mathrm{pH}$ ranges have not been reported. $W$. virosa grows on McConkey agar, indicating tolerance to bile salts [1] . On the other hand, KCN (75 $\left.\mathrm{mg} \mathrm{l}^{-1}\right)$, cetrimide, colistin [17], and polymyxin [5] are not tolerated and inhibit growth. The species is able to utilize $\beta$-hydroxybutyrate as a substrate and to hydrolyze casein, gelatin and Tween $20[1,17]$. Tryptophan is cleaved to give indole, pyruvate and ammonia when tested with Ehrlich's reagent, but the reaction can not be detected when Kovacs' reagent is used [1] . W. virosa is inert in most traditional biochemical tests [1], it does not utilize glucose as a substrate under standard conditions [16]. W. virosa does not hydrolyze starch, esculin or DNA, and is negative for gluconate oxidation, urease, phenylalanine deaminase, arginine deaminase, arginine dihydrolase, lysine or ornithine decarboxylase, $\beta$-D-galactosidase [1], alkalization of galacturonate [17]. The following enzymes are present as concluded from tests using API ZYM galleries: acid and alkaline phosphatase, lysine arylamidase, aspartate arylamidase, alanine arylamidase and methionine arylamidase [1]. In addition, the following substrates were hydrolyzed in the latter galleries by $W$. virosa: naphthol-AS-BIphosphodiamide, bis-(para-nitrophenyl)phosphate, glycyl-glycyl- $\beta$-naphthylamide hydrobromide, glycyl-L-phenylalanyl- $\beta$-naphthylamide, glycyl-L-prolyl- $\beta$-naphthylamide, L-leucyl-glycyl$\beta$-naphthylamide, $\alpha$-L-glutamyl- $\beta$-naphthylamide, and $\mathrm{N}$-carbobenzoxy-glycyl-glycyl-L-arginine- $\beta$ naphthylamide [1]. $W$. virosa is susceptible to most $\beta$-lactams, tetracycline, chloramphenicol, nalidixic acid, erythromycin and sulfamethoxazole-trimethoprim [11]. In contrast, the species is resistant to aminoglycosides [11].

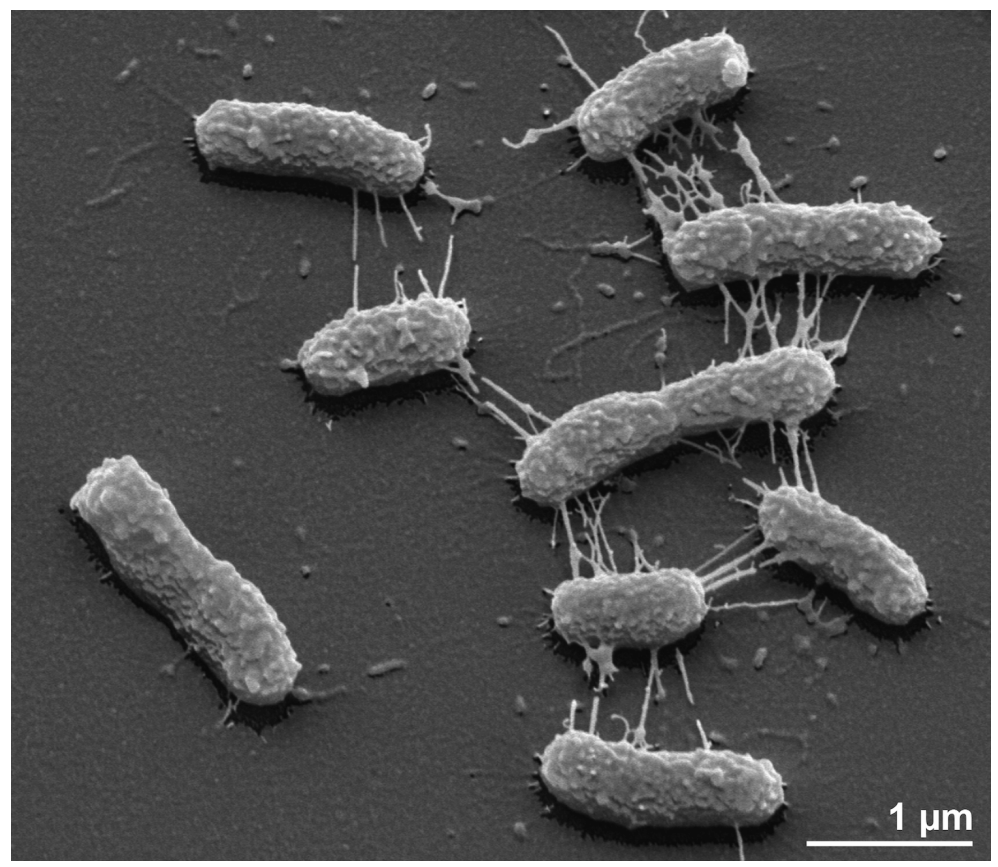

Figure 2. Scanning electron micrograph of $W$. virosa strain $9751^{\top}$ 
Table 1. Classification and general features of $W$. virosa $9751^{\top}$ according to the MIGS recommendations [25].

\begin{tabular}{|c|c|c|c|}
\hline MIGS ID & Property & Term & Evidence code \\
\hline & \multirow{8}{*}{ Current classification } & Domain Bacteria & TAS [26] \\
\hline & & Phylum Bacteroidetes & TAS [27] \\
\hline & & Class 'Flavobacteria' & TAS [28] \\
\hline & & Order 'Flavobacteriales' & TAS [29] \\
\hline & & Family Flavobacteriaceae & TAS [30-33] \\
\hline & & Genus Weeksella & TAS $[1,34]$ \\
\hline & & Species Weeksella virosa & TAS $[1,34]$ \\
\hline & & Type strain 9751 (= CL345/78) & TAS $[1,34]$ \\
\hline & Gram stain & negative & TAS [1] \\
\hline & Cell shape & rod-shaped & TAS [1] \\
\hline & Motility & non-motile & TAS [1] \\
\hline & Sporulation & none & TAS [1] \\
\hline & Temperature range & $10^{\circ} \mathrm{C}$ or less up to $42^{\circ} \mathrm{C}$ & TAS [1] \\
\hline & Optimum temperature & not reported & NAS \\
\hline & Salinity & not reported & NAS \\
\hline \multirow[t]{3}{*}{ MIGS-22 } & Oxygen requirement & aerobic & TAS [1] \\
\hline & Carbon source & proteins & TAS [1] \\
\hline & Energy source & chemoorganotroph & TAS [1] \\
\hline MIGS-6 & Habitat & human urogenital tract & TAS $[1,4]$ \\
\hline MIGS-15 & Biotic relationship & saprophyte & TAS $[1,11]$ \\
\hline \multirow[t]{3}{*}{ MIGS-14 } & Pathogenicity & none & NAS \\
\hline & Biosafety level & 1 & TAS [35] \\
\hline & Isolation & human urine & TAS [1] \\
\hline MIGS-4 & Geographic location & North Carolina, USA & TAS [1] \\
\hline MIGS-5 & Sample collection time & 1986 or before & TAS [1] \\
\hline MIGS-4.1 & Latitude & not reported & NAS \\
\hline MIGS-4.2 & Longitude & not reported & NAS \\
\hline MIGS-4.3 & Depth & not reported & NAS \\
\hline MIGS-4.4 & Altitude & not reported & NAS \\
\hline
\end{tabular}

Evidence codes - IDA: Inferred from Direct Assay (first time in publication); TAS: Traceable Author Statement (i.e., a direct report exists in the literature); NAS: Non-traceable Author Statement (i.e., not directly observed for the living, isolated sample, but based on a generally accepted property for the species, or anecdotal evidence). These evidence codes are from of the Gene Ontology project [36]. If the evidence code is IDA, then the property was directly observed by one of the authors or an expert mentioned in the acknowledgements.

\section{Chemotaxonomy}

The major respiratory quinone of $W$. virosa is menaquinone 6 and the major polyamine is homospermidine, as is the case for all members of the family Flavobacteriaceae [11,38-40]. No sphingophospholipids were detected [1]. The polar lipids of $W$. virosa have not yet been described. The major whole-cell fatty acids of $W$. virosa are iso- $\mathrm{C}_{15: 0}$ (46\%), iso- $\mathrm{C}_{15: 0} 2-\mathrm{OH}(10 \%)$, iso- $\mathrm{C}_{17: 1} \omega 12 \mathrm{t}(8 \%)$ and iso- $\mathrm{C}_{17: 0} 3-\mathrm{OH}(7 \%)$ as described for CDC group IIf, the preliminary name given to these strains prior to being formally named $W$. virosa [41]. A comparison of the patterns of $W$. virosa and ' $W$. zoohelcum' obtained at that time [41] with more recently published patterns of $B$. zoohelcum and $E$. brevis and phylogenetic neighbors $[17,19]$ seems to cast doubts on the comparability of these early patterns. They are the only ones listing the presence of high amounts of iso- $\mathrm{C}_{15: 0} 2-\mathrm{OH}$ and iso$\mathrm{C}_{17: 1} \omega 12 \mathrm{t}$, which are not listed for phylogenetically related genera later on [19]. However, iso- $\mathrm{C}_{15: 0} 2$ $\mathrm{OH}$ and isomers of iso-heptadecene are included in the summed features of the Microbial Identification System applied in many recent analyses including $[17,19]$. 


\section{Genome sequencing and annotation}

\section{Genome project history}

This organism was selected for sequencing on the basis of its phylogenetic position [42], and is part of the Genomic Encyclopedia of Bacteria and Archaea project [40]. The genome project is deposited in the Genomes OnLine Database [23] and the complete genome sequence is deposited in GenBank. Sequencing, finishing and annotation were performed by the DOE Joint Genome Institute (JGI). A summary of the project information is shown in Table 2.

Table 2. Genome sequencing project information

\begin{tabular}{lll}
\hline MIGS ID & Property & Term \\
\hline MIGS-31 & Finishing quality & Finished \\
MIGS-28 & Libraries used & Tree genomic libraries: one 454 pyrosequence standard library, \\
one 454 PE library (17 kb insert size), one Illumina library \\
MIGS-29 & Sequencing platforms & Illumina GAii, 454 GS FLX Titanium \\
MIGS-31.2 & Sequencing coverage & $2,107.5 \times$ Illumina; $64.3 \times$ pyrosequence \\
MIGS-30 & Assemblers & Newbler version 2.5-internal-10Apr08-1-threads, Velvet version \\
MIGS-32 & Gene calling method & Prodigal 1.4, GenePRIMP \\
& INSDC ID & CP02455 \\
& Genbank Date of Release & February 15, 2011 \\
& GOLD ID & Gc01619 \\
& NCBI project ID & 50581 \\
& Database: IMG-GEBA & 2503754024 \\
MIGS-13 & Source material identifier & DSM 16922 \\
& Project relevance & Tree of Life, GEBA \\
\hline
\end{tabular}

\section{Growth conditions and DNA isolation}

W. virosa $9751^{\mathrm{T}}$, DSM 16922, was grown on DSMZ medium 220 (Caso Agar) [37] at $30^{\circ} \mathrm{C}$. DNA was isolated from $0.5-1 \mathrm{~g}$ of cell paste using MasterPure Gram-positive DNA purification kit (Epicentre MGP04100) following the standard protocol as recommended by the manufacturer, with modification st/DL for cell lysis as described in Wu et al. [43]. DNA is available through the DNA Bank Network $[44,45]$.

\section{Genome sequencing and assembly}

The genome was sequenced using a combination of Illumina and 454 sequencing platforms. All general aspects of library construction and sequencing can be found at the JGI website [46]. Pyrosequencing reads were assembled using the Newbler assembler version 2.5-internal-10Apr08-1threads (Roche). The initial Newbler assembly consisting of 27 contigs in one scaffold was converted into a phrap assembly by making fake reads from the consensus, to collect the read pairs in the 454 paired end library. Illumina GAii sequencing data $(4,788 \mathrm{Mb})$ was assembled with Velvet [47] and the consensus sequences were shredded into $1.5 \mathrm{~kb}$ overlapped fake reads and assembled together with the 454 data. The 454 draft assembly was based on $131.6 \mathrm{Mb} 454 \mathrm{draft}$ data and all of the 454 paired end data. Newbler parameters are -consed -a 50 -l 350 -g -m -ml 20. The Phred/Phrap/Consed software package [48] was used for sequence assembly and quality assessment in the subsequent finishing process. After the shotgun stage, reads were assembled with parallel phrap (High Performance Software, LLC). Possible mis-assemblies were corrected with gapResolution, Dupfinisher [49], or sequencing cloned bridging PCR fragments with subcloning or transposon bombing (Epicentre Biotechnologies, Madison, WI). Gaps between contigs were closed by editing in Consed, by PCR and by Bubble PCR primer walks (J.-F.Chang, unpublished). A total of 60 additional reactions were necessary to close gaps and to raise the quality of the finished sequence. Illumina reads were also used to correct potential base errors and increase consensus quality using a software Polisher developed at JGI [50]. The error rate of the completed genome sequence is less than one in 100,000 . Together, the combi- 
nation of the Illumina and 454 sequencing platforms provided 2,171.8 $\times$ coverage of the genome. The final assembly contained 384,925 pyrosequence and 63,008,730 Illumina reads.

\section{Genome annotation}

Genes were identified using Prodigal [51] as part of the Oak Ridge National Laboratory genome annotation pipeline, followed by a round of manual curation using the JGI GenePRIMP pipeline [52]. The predicted CDSs were translated and used to search the National Center for Biotechnology Information (NCBI) nonredundant database, UniProt, TIGR-Fam, Pfam, PRIAM, KEGG, COG, and InterPro databases. Additional gene prediction analysis and functional annotation was performed within the Integrated Microbial Genomes - Expert Review (IMG-ER) platform [53].

\section{Genome properties}

The genome consists of a 2,272,954 bp long chromosome with a GC content of $35.9 \%$ (Figure 3 and Table 3). Of the 2,181 genes predicted, 2,105 were protein-coding genes, and 76 RNAs; 56 pseudogenes were also identified. The majority of the protein-coding genes $(65.5 \%)$ were assigned with a putative function while the remaining ones were annotated as hypothetical proteins. The distribution of genes into COGs functional categories is presented in Table 4.

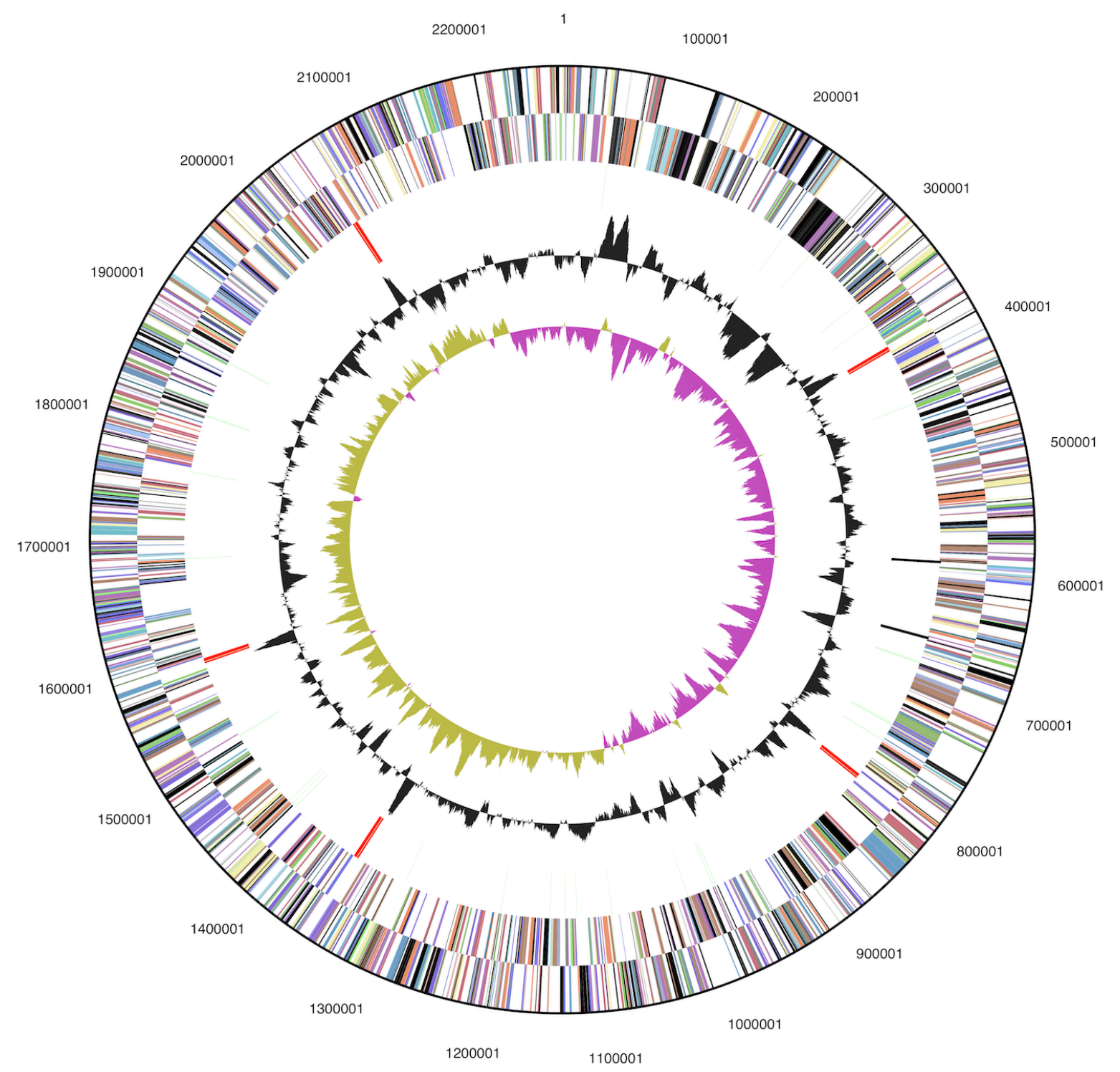

Figure 3. Graphical circular map of the chromosome. From outside to the center: Genes on forward strand (color by COG categories), Genes on reverse strand (color by COG categories), RNA genes (tRNAs green, rRNAs red, other RNAs black), GC content, GC skew. 
Table 3. Genome Statistics

\begin{tabular}{lrr}
\hline Attribute & Value & \% of Total \\
\hline Genome size (bp) & $2,272,954$ & $100.00 \%$ \\
DNA coding region (bp) & $2,037,648$ & $89.65 \%$ \\
DNA G+C content (bp) & 816,484 & $35.92 \%$ \\
Number of replicons & 1 & \\
Extrachromosomal elements & 0 & \\
Total genes & 2,181 & $100.00 \%$ \\
RNA genes & 76 & $3.48 \%$ \\
rRNA operons & 5 & \\
Protein-coding genes & 2,105 & $96.52 \%$ \\
Pseudo genes & 56 & $2.57 \%$ \\
Genes with function prediction & 1,429 & $65.52 \%$ \\
Genes in paralog clusters & 99 & $4.54 \%$ \\
Genes assigned to COGs & 1,403 & $64.33 \%$ \\
Genes assigned Pfam domains & 1,534 & $70.33 \%$ \\
Genes with signal peptides & 506 & $23.20 \%$ \\
Genes with transmembrane helices & 451 & $20.68 \%$ \\
CRISPR repeats & 1 & \\
\hline
\end{tabular}

Table 4. Number of genes associated with the general COG functional categories

\begin{tabular}{lrrl}
\hline Code & value & \%age & Description \\
\hline J & 142 & 9.5 & Translation, ribosomal structure and biogenesis \\
A & 0 & 0.0 & RNA processing and modification \\
K & 54 & 3.6 & Transcription \\
L & 94 & 6.3 & Replication, recombination and repair \\
B & 0 & 0.0 & Chromatin structure and dynamics \\
D & 18 & 1.2 & Cell cycle control, cell division, chromosome partitioning \\
Y & 0 & 0.0 & Nuclear structure \\
V & 29 & 1.9 & Defense mechanisms \\
T & 29 & 1.9 & Signal transduction mechanisms \\
M & 154 & 10.3 & Cell wall/membrane/envelope biogenesis \\
N & 4 & 0.3 & Cell motility \\
Z & 0 & 0.0 & Cytoskeleton \\
W & 0 & 0.0 & Extracellular structures \\
U & 25 & 1.7 & Intracellular trafficking, secretion, and vesicular transport \\
O & 73 & 4.9 & Posttranslational modification, protein turnover, chaperones \\
C & 82 & 5.5 & Energy production and conversion \\
G & 47 & 3.1 & Carbohydrate transport and metabolism \\
E & 127 & 8.5 & Amino acid transport and metabolism \\
F & 57 & 3.8 & Nucleotide transport and metabolism \\
H & 95 & 6.3 & Coenzyme transport and metabolism \\
I & 72 & 4.8 & Lipid transport and metabolism \\
P & 101 & 6.7 & Inorganic ion transport and metabolism \\
Q & 24 & 1.6 & Secondary metabolites biosynthesis, transport and catabolism \\
R & 171 & 11.4 & General function prediction only \\
S & 103 & 6.9 & Function unknown \\
- & 778 & 35.7 & Not in CoGs \\
\hline
\end{tabular}




\section{Acknowledgements}

This work was performed under the auspices of the US Department of Energy Office of Science, Biological and Environmental Research Program, and by the University of California, Lawrence Berkeley National Laboratory under contract No. DE-AC02-05CH11231, Lawrence Livermore National Laboratory under Contract No. DE-

\section{References}

1. Holmes B, Steigerwaldt AG, Weaver RE, Brenner DJ. Weeksella virosa gen. nov., sp. nov. (formerly group IIf) found in human clinical specimens. Syst Appl Microbiol 1986; 8:185-190.

2. Garrity G. NamesforLife. BrowserTool takes expertise out of the database and puts it right in the browser. Microbiol Today 2010; 37:9.

3. Leung WK, Jin LJ, Yam WC, Samaranayake LP. Oral colonization of aerobic and facultatively anaerobic gram-negative rods and cocci in irradiated, dentate, xerostomic individuals. Oral Microbiol Immunol 2001; 16:1-9. PubMed doi:10.1034/j.1399-302x.2001.160101.x

4. Mardy C, Holmes B. Incidence of vaginal Weeksella virosa (formerly group IIf). J Clin Pathol 1988; 41:211-214. PubMed doi:10.1136/jcp.41.2.211

5. Reina J, Gil J, Salva F, Gomez J, Alomar P. Microbiological characteristics of Weeksella virosa (formerly CDC group IIf) isolated from the human genitourinary tract. J Clin Microbiol 1990; 28:2357-2359. PubMed

6. Vela Al, García N, Latre MV, Casamayor A, Sánchez-Porro C, Briones V, Ventosa A, Domínguez L, Fernández-Garayzábal JF. Aerococcus suis sp. nov., isolated from clinical specimens from swine. Int J Syst Evol Microbiol 2007; 57:1291-1294. PubMed doi:10.1099/ijs.0.64537-0

7. Brun R, Urraro C, Medaglia C, Russo V, Borzacchiello G, Roperto F, Roperto S. Lymphoepithelioma-like carcinoma of the urinary bladder in a cow associated with bovine papillomavirus type-2. J Comp Pathol 2008; 139:121-125. Published online August 3, 2008. PubMed doi:10.1016/j.jcpa.2008.06.002

8. Gouveia C, Asensi MD, Zahner V, Rangel EF, Oliveira SM. Study on the bacterial midgut microbiota associated to different Brazilian populations of Lutzomyia longipalpis (Lutz \& Neiva) (Diptera: Psychodidae). Neotrop Entomol 2008; 37:597-601. PubMed doi:10.1590/S1519566X2008000500016

9. Botha WC, Jooste PJ, Hugo CJ. The incidence of Weeksella- and Bergeyella-like bacteria in the
AC52-07NA27344, and Los Alamos National Laboratory under contract No. DE-AC02-06NA25396, UTBattelle and Oak Ridge National Laboratory under contract DE-AC05-000R22725, as well as German Research Foundation (DFG) INST 599/1-2.

food environment. J App/ Microbiol 1998;

84:349-356. PubMed doi:10.1046/j.13652672.1998.00346.x

10. Botha WC, Jooste PJ, Britz TJ. The taxonomic relationship of certain environmental flavobacteria to the genus Weeksella. I Appl Bacteriol 1989; 67:551-559. PubMed

11. Hugo CJ, Bruun B, Jooste PJ. The genera Bergeyella and Weeksella. In: The Prokaryotes, vol. 7: Proteobacteria: Delta, Epsilon Subclass. Dworkin M, Falkow S, Rosenberg E, Schleifer K-H and Stackebrandt E (eds). 2006; 523-538.

12. Boixeda D, de Luis DA, Meseguer MA, Aller R, Martin de Argila C. Lopez Sanroman. A case of spontaneous peritonitis caused by Weeksella virosa. Eur J Gastroenterol Hepatol 1998; 10:897-898. PubMed doi:10.1097/00042737-199810000$\underline{00016}$

13. Pattengale ND, Alipour M, Bininda-Emonds ORP, Moret BME, Stamatakis A. How many bootstrap replicates are necessary? Lect Notes Comput Sci 2009; 5541:184-200. doi:10.1007/978-3-642$\underline{02008-7 \quad 13}$

14. DeSantis TZ, Hugenholtz P, Larsen N, Rojas M, Brodie EL, Keller K, Huber T, Dalevi D, Hu P, Andersen GL. Greengenes, a Chimera-Checked $16 \mathrm{~S}$ rRNA Gene Database and Workbench Compatible with ARB. Appl Environ Microbiol 2006; 72:5069-5072. PubMed doi:10.1128/AEM.03006$\underline{05}$

15. Porter MF. An algorithm for suffix stripping. Program: electronic library and information systems 1980; 14:130-137.

16. Bernardet JF, Nakagawa Y. An introduction to the family Flavobacteriaceae. In: The Prokaryotes, vol. 7: Proteobacteria: Delta, Epsilon Subclass. Dworkin M, Falkow S, Rosenberg E, Schleifer K-H and Stackebrandt E (eds). 2006; 455-480.

17. Kämpfer $P$, Avesani $V$, Janssens $M$, Charlier J, De Baere T, Vaneechoutte M. Description of Wautersiella falsenii gen. nov., sp. nov., to accommodate clinical isolates phenotypically resembling members of the genera Chryseobacterium and Empe- 
Lang et al.

dobacter. Int J Syst Evol Microbiol 2006; 56:23232329. PubMed doi:10.1099/ijs.0.64393-0

18. O'Sullivan LA, Rinna J, Humphreys G, Weightman AJ, Fry JC. Culturable phylogenetic diversity of the phylum 'Bacteroidetes' from river epilithon and coastal water and description of novel members of the family Flavobacteriaceae: Epilithonimonas tenax gen. nov., sp. nov. and Persicivirga xylanidelens gen.nov., sp. nov. Int J Syst Evol Microbiol 2006; 56:169-180. PubMed doi:10.1099/ijs.0.63941-0

19. Hugo CJ, Segers P, Hoste B, Vancanneyt M, Kersters K. Chryseobacterium joostei sp. nov., isolated from the dairy environment. Int / Syst Evol Microbiol 2003; 53:771-777. PubMed doi:10.1099/ijs.0.02232-0

20. Castresana J. Selection of conserved blocks from multiple alignments for their use in phylogenetic analysis. Mol Biol Evol 2000; 17:540-552. PubMed

21. Lee C, Grasso C, Sharlow MF. Multiple sequence alignment using partial order graphs. Bioinformatics 2002; 18:452-464. PubMed doi:10.1093/bioinformatics/18.3.452

22. Stamatakis A, Hoover $P$, Rougemont J. A rapid bootstrap algorithm for the RAxML Web servers. Syst Biol 2008; 57:758-771. PubMed doi:10.1080/10635150802429642

23. Liolios K, Chen IM, Mavromatis K, Tavernarakis N, Hugenholtz P, Markowitz VM, Kyrpides NC. The Genomes On Line Database (GOLD) in 2009: status of genomic and metagenomic projects and their associated metadata. Nucleic Acids Res 2010; 38:D346-D354. PubMed doi:10.1093/nar/gkp848

24. Han C, Goodwin L, Pitluck S, Liolios L, Pagani I, Ivanova N, Mikhailova N, Pati A, Chen A, Palianappan $\mathrm{K}$, et al. Complete genome sequence of Riemerella anatipestifer type strain (Bruner $\left.{ }^{\top}\right)$. Stand Genomic Sci 2011; 4(2).

25. Field D, Garrity G, Gray T, Morrison N, Selengut J, Sterk P, Tatusova T, Thomson N, Allen MJ, Angiuoli SV, et al. The minimum information about a genome sequence (MIGS) specification. Nat Biotechnol 2008; 26:541-547. PubMed doi:10.1038/nbt1360

26. Woese CR, Kandler O, Wheelis ML. Towards a natural system of organisms: proposal for the domains Archaea, Bacteria, and Eucarya. Proc Natl Acad Sci USA 1990; 87:4576-4579. PubMed doi:10.1073/pnas.87.12.4576
27. Garrity GM, Holt JG. The Road Map to the Manual. In: Garrity GM, Boone DR, Castenholz RW (eds), Bergey's Manual of Systematic Bacteriology, Second Edition, Volume 1, Springer, New York, 2001, p. 119-169.

28. Ludwig W, Euzeby J, Whitman WG. Draft taxonomic outline of the Bacteroidetes, Planctomycetes, Chlamydiae, Spirochaetes, Fibrobacteres, Fusobacteria, Acidobacteria, Verrucomicrobia, Dictyoglomi, and Gemmatimonadetes. http://www.bergeys.org/outlines/Bergeys_Vol_4_ Outline.pdf. Taxonomic Outline 2008

29. Garrity GM, Holt JG. 2001. Taxonomic outline of the Archaea and Bacteria, p. 155-166. In G. M. Garrity, D. R. Boone, and R. W. Castenholz (ed.), Bergey's Manual of Systematic Bacteriology, 2nd ed, vol. 1. Springer, New York.

30. Validation of the publication of new names and new combinations previously effectively published outside the IJSB. List No. 41. Int / Syst Bacteriol 1992; 42:327-328. doi:10.1099/0020771342-2-327

31. Reichenbach H. Order 1. Cytophagales Leadbetter 1974, 99AL. In: Holt JG (ed), Bergey's Manual of Systematic Bacteriology, First Edition, Volume 3, The Williams and Wilkins Co., Baltimore, 1989, p. 2011-2013.

32. Bernardet JF, Segers $P$, Vancanneyt $M$, Berthe $F$, Kersters K, Vandamme P. Cutting a Gordian knot: emended classification and description of the genus Flavobacterium, emended description of the family Flavobacteriaceae, and proposal of Flavobacterium hydatis nom. nov. (Basonym, Cytophaga aquatilis Strohl and Tait 1978). Int J Syst Bacteriol 1996; 46:128-148. doi:10.1099/00207713$\underline{46-1-128}$

33. Bernardet JF, Nakagawa Y, Holmes B. Proposed minimal standards for describing new taxa of the family Flavobacteriaceae, and emended description of the family. Int / Syst Evol Microbiol 2002; 52:1049-1070. PubMed doi:10.1099/ijs.0.02136$\underline{0}$

34. Validation list $\mathrm{No}^{\circ}$ 23. Int J Syst Bacteriol 1987; 37:179-180. doi:10.1099/00207713-37-2-179

35. Classification of bacteria and archaea in risk groups. http://www.baua.de TRBA 466.

36. Ashburner M, Ball CA, Blake JA, Botstein D, Butler H, Cherry JM, Davis AP, Dolinski K, Dwight SS, Eppig JT, et al. Gene Ontology: tool for the unification of biology. Nat Genet 2000; 25:25-29. $\underline{\text { PubMed doi:10.1038/75556 }}$ 
37. List of growth media used at DSMZ: http://www.dsmz.de/microorganisms/media_list.p hp.

38. Vandamme P, Bernardet JF, Segers P, Kersters K, Holmes B. New perspectives in the classification of the flavobacteria: description of Chryseobacterium gen. nov., Bergeyella gen. nov., and Empedobacter nom. rev. Int J Syst Bacteriol 1994; 44:827-831. doi:10.1099/00207713-44-4-827

39. Bernardet JF, Nakagawa Y, Holmes B. Proposed minimal standards for describing new taxa of the family Flavobacteriaceae and emended description of the family. Int / Syst Evol Microbiol 2002; 52:1049-1070. PubMed doi:10.1099/ijs.0.02136$\underline{0}$

40. Hamana K, Nakagawa Y. Polyamine distribution profiles in the eighteen genera phylogenetically located within the Flavobacterium-FlexibacterCytophaga complex. Microbios 2001; 106:7-17. PubMed

41. Hollis DG, Daneshvar MI, Moss CW, Baker CN. Phenotypic characteristics, fatty acid composition, and isoprenoid quinone content of CDC group IIg bacteria. J Clin Microbiol 1995; 33:762-764. PubMed

42. Klenk HP, Göker M. En route to a genome-based classification of Archaea and Bacteria? Syst Appl Microbiol 2010; 33:175-182. PubMed doi:10.1016/j.syapm.2010.03.003

43. Wu D, Hugenholtz P, Mavromatis K, Pukall R, Dalin E, Ivanova NN, Kunin V, Goodwin L, Wu $M$, Tindall $B$ J, et al. A phylogeny-driven genomic encyclopaedia of Bacteria and Archaea. Nature 2009; 462:1056-1060. PubMed doi:10.1038/nature08656

44. Gemeinholzer B, Dröge G, Zetzsche H, Haszprunar G, Klenk HP, Güntsch A, Berendsohn WG, Wägele JW. The DNA Bank Network: the start from a German initiative. Biopreservation and Biobanking (In press).
45. DNA bank Network. http://www.dnabanknetwork.org

46. DOE Joint Genome Institute. http://www.jgi.doe.gov

47. Zerbino DR, Birney E. Velvet: algorithms for de novo short read assembly using de Bruijn graphs. Genome Res 2008; 18:821-829. PubMed doi:10.1101/gr.074492.107

48. Phrap and Phred for Windows. MacOS, Linux, and Unix. http://www.phrap.com

49. Han C, Chain P. 2006. Finishing repeat regions automatically with Dupfinisher. Proceeding of the 2006 international conference on bioinformatics \& computational biology. Edited by Hamid R. Arabnia \& Homayoun Valafar, CSREA Press. June 26-29, 2006: 141-146.

50. Lapidus A, LaButti K, Foster B, Lowry S, Trong S, Goltsman E. POLISHER: An effective tool for using ultra short reads in microbial genome assembly and finishing. AGBT, Marco Island, FL, 2008.

51. Hyatt D, Chen GL, LoCascio PF, Land ML, Larimer FW, Hauser LJ. Prodigal: prokaryotic gene recognition and translation initiation site identification. BMC Bioinformatics 2010; 11:119. PubMed doi:10.1186/1471-2105-11-119

52. Pati A, Ivanova NN, Mikhailova N, Ovchinnikova G, Hooper SD, Lykidis A, Kyrpides NC. GenePRIMP: a gene prediction improvement pipeline for prokaryotic genomes. Nat Methods 2010; 7:455-457. PubMed doi:10.1038/nmeth.1457

53. Markowitz VM, Ivanova NN, Chen IMA, Chu K, Kyrpides NC. IMG ER: a system for microbial genome annotation expert review and curation. Bioinformatics 2009; 25:2271-2278. PubMed doi:10.1093/bioinformatics/btp393

54. Faber MD, del Busto R, Cruz C, Mezger E. Response of Weeksella virosa peritonitis to imipenem/cilastin. Adv Perit Dial 1991; 7:133-134. PubMed 